\title{
Recent developments in nanotoxicology
}

\author{
H. M. Bolt • R. Marchan - J. G. Hengstler
}

Published online: 17 April 2012

(C) Springer-Verlag 2012

Nanotoxicology addresses the adverse effects of manufactured nanomaterials in biological systems (Weiss and Diabaté 2011). A particularly attractive feature of this discipline is that it brings together scientists from various disciplines, including toxicology, physics, chemistry, biology, medicine and engineering. Although a lot of progress has been made in recent years, some key questions are still not yet sufficiently answered:

- To which degree are the ions released from the nanoparticles responsible for toxic effects?

- To which degree do the physical properties (size, shape, agglomeration) of the nanoparticles contribute to its toxicity?

- Can nanoparticles accumulate in the body? If yes, in which cell types and subcellular structures?

- How can in vitro tests contribute to risk assessment?

- To which degree does oxidative stress explain toxicity of nanoparticles?

The editors are pleased that Carsten Weiss and Silvia Diabaté from the Karlsruhe Institute of Technology organized a special issue addressing these key questions. The articles are highly recommended to all who are interested in nanotoxicology (Table 1).
H. M. Bolt $(\bowtie) \cdot$ R. Marchan · J. G. Hengstler Leibniz Research Centre for Working Environment and Human Factors (IfADo), Ardeystrasse 67, 44139 Dortmund, Germany

e-mail: bolt@ifado.de
Table 1 Key messages from the recently published special issue on nanotoxicology (Weiss and Diabaté 2011)

\begin{tabular}{ll}
\hline Key messages & References \\
\hline Quantum dots are frequently used to & Hoshino et al. (2011) \\
label cells. This article reviews the & \\
toxicity and biological behaviour of & \\
quantum dots and reports that the & \\
capping material, rather than the care & \\
complex, is relevant for toxic effects & \\
This article reviews possibilities and & Clift et al. (2011) (review) \\
limitations of in vitro testing in & \\
nanotoxicology & \\
Nanoparticles can activate various & Marano et al. (2011) \\
signalling pathways including ERK, & \\
p38, JNK as well as NF $\kappa$ B and Nrf-2. & \\
Interestingly, when these pathways are & \\
activated, oxidative stress is observed. & \\
This article demonstrates that not all & \\
toxic effects of nanoparticles can be & \\
explained by oxidative stress & \\
Silver nanoparticles cause oxidative & Foldbjerg et al. (2011) \\
stress and induce bulky DNA adducts & \\
in a human lung cancer cell line & \\
Industrially manufactured nanoparticles & Gibson et al. (2011) \\
can be radiolabelled by a cyclotron- & \\
based irradiation technique and are & \\
suitable for in vitro and in vivo tracing & \\
studies & \\
High-aspect carbon nanotubes & \\
(diameter, 10-15 nm; length, 10 $\mu$ m) & \\
are more cytotoxic than low-aspect & \\
nanotubes (diameter, 10-15 nm; & \\
length, 150 nm). However, both high- & \\
and low-aspect nanotubes were & \\
negative in the Ames test, in vitro \\
chromosome aberration test and in \\
vivo micronuclei test \\
\hline
\end{tabular}


Table 1 continued

\begin{tabular}{ll}
\hline Key messages & References \\
\hline $\begin{array}{l}\text { Depending on the type of } \\
\text { functionalization, lead sulphide }\end{array}$ & Truong et al. (2011) \\
nanoparticles show different degrees & \\
of toxicity to embryonic zebrafish. & \\
This may be explained by the different & \\
extent of released soluble lead ions & \\
DNA strand breaks observed after & Gehrke et al. (2011) \\
incubation of colon carcinoma cells & \\
with platinum nanoparticles are & \\
caused by released platinum ions & \\
Silica nanoparticles accumulate in & Al-Rawi et al. (2011) \\
endosomes of HeLa cells. In contrast, & \\
they do not accumulate in nuclei or & \\
mitochondria & \\
The capacity of titanium dioxide & Leppänen et al. (2011) \\
nanoparticles to induce pulmonary & \\
irritation and inflammation in mice is & \\
low & \\
\hline
\end{tabular}

\section{References}

Al-Rawi M, Diabaté S, Weiss C (2011) Uptake and intracellular localization of submicron and nano-sized $\mathrm{SiO}_{2}$ particles in HeLa cells. Arch Toxicol 85(7):813-826

Clift MJD, Gehr P, Rothen-Rutishauser B (2011) Nanotoxicology: a perspective and discussion of whether or not in vitro testing is a valid alternative. Arch Toxicol 85:723-731

Foldbjerg R, Dang DA, Autrup H (2011) Cytotoxicity and genotoxicity of silver nanoparticles in the human lung cancer cell line, A549. Arch Toxicol 85(7):743-750
Gehrke H, Pelka J, Hartinger CG, Blank H, Bleimund F, Schneider R, Gerthsen D, Bräse S, Crone M, Türk M, Marko D (2011) Platinum nanoparticles and their cellular uptake and DNA platination at non-cytotoxic concentrations. Arch Toxicol 85(7):799-812

Gibson N, Holzwarth U, Abbas K, Simonelli F, Kozempel J, Cydzik I, Cotogno G, Bulgheroni A, Gilliland D, Ponti J, Franchini F, Marmorato P, Stamm H, Kreyling W, Wenk A, SemmlerBehnke M, Buono S, Maciocco L, Burgio N (2011) Radiolabelling of engineered nanoparticles for in vitro and in vivo tracing applications using cyclotron accelerators. Arch Toxicol 85(7):751-773

Hoshino A, Hanada S, Yamamoto K (2011) Toxicity of nanocrystal quantum dots: the relevance of surface modifications. Arch Toxicol 85(7):707-720

Kim JS, Lee K, Lee YH, Cho HS, Kim KH, Choi KH, Lee SH, Song KS, Kang CS, Yu IJ (2011) Aspect ratio has no effect on genotoxicity of multi-wall carbon nanotubes. Arch Toxicol 85(7):775-786

Leppänen M, Korpi A, Miettinen M, Leskinen J, Torvela T, Rossi EM, Vanhala E, Wolff H, Alenius H, Kosma VM, Joutsensaari J, Jokiniemi J, Pasanen P (2011) Nanosized $\mathrm{TiO}_{2}$ caused minor airflow limitation in the murine airways. Arch Toxicol 85(7):827-839

Marano F, Hussain S, Rodrigues-Lima F, Baeza-Squiban A, Boland S (2011) Nanoparticles: molecular targets and cell signalling. Arch Toxicol 85(7):733-741

Truong L, Moody IS, Stankus DP, Nason JA, Lonergan MC, Tanguay RL (2011) Differential stability of lead sulfide nanoparticles influences biological responses in embryonic zebrafish. Arch Toxicol 85(7):787-798

Weiss C, Diabaté S (2011) A special issue on nanotoxicology. Arch Toxicol 85:705-706 